\title{
Documento de la Academia Chilena de Medicina** sobre las relaciones entre los médicos y la industria proveedora en salud* (parte I)
}

La Academia Chilena de Medicina valora la contribución que la industria proveedora en salud* realiza para el progreso de la medicina y para el beneficio de las acciones en salud. No obstante, tiene presente que los intereses primarios de los médicos, de los pacientes y de la industria son diferentes, por lo que suelen generarse situaciones de conflicto entre ellos. En tales casos los médicos deben tener presente su compromiso irrenunciable de que siempre prime el beneficio de sus pacientes.

Distintas sociedades científicas y agrupaciones médicas, universidades, colegios profesionales y la misma industria, han publicado diversos documentos referidos a las relaciones de los médicos con la industria proveedora en salud. Algunos de ellos, particularmente en países de Norteamérica y Europa, incluyen sanciones para quienes contravengan las normas establecidas. Debe tenerse presente que el contexto cultural de estos países es diferente del nuestro, donde existe una arraigada tradición de recurrir a la industria proveedora para financiar las más diversas actividades de educación médica continua, tanto a nivel personal como corporativo. La Academia Chilena de Medicina desea llamar la atención de los profesionales y guiarlos para que, en todo tipo de situaciones potencialmente conflictivas entre los actores relacionados con la actividad clínica, los médicos mantengan plena autonomía profesional en la toma de decisiones, evitando sesgos que puedan influir en ellas, evaluando la evidencia científica de los diferentes productos que se promocionan y haciendo primar siempre los intereses de los pacientes sobre los de otra persona o grupos de personas.

La Academia de Medicina recomienda que la relación entre los médicos y la industria se caracterice siempre y en toda circunstancia por una total transparencia, que respalde la confianza del público, de los pacientes y de todos los actores involucrados en este proceso. La información sesgada o de menor confiabilidad aumenta la probabilidad de errores médicos, disminuyendo la calidad y efectividad de la acción terapéutica. Los médicos deben estar atentos para reconocer la presencia de intereses promocionales o comerciales y ser críticos de la información que reciben.

La industria proveedora se relaciona con los médicos clínicos a través de múltiples formas, intentando influir directa o indirectamente en las decisiones diagnósticas o terapéuticas:

1. Difundiendo información médica favorable a sus productos.

2. Brindando atenciones (desayunos, almuerzos o cenas en relación a reuniones médicas, con regalos personales u otros).

3. Invitando y financiando la asistencia a eventos en el país o en el extranjero.

4. Contribuyendo a realizar y financiar eventos científicos organizados por sociedades académicas, universidades o grupos de profesionales, ya sea pagando para disponer de espacios de exhibición de productos, agasajando a los asistentes, invitando a expositores o participantes, organizando actividades paralelas "satélites", donando material de trabajo, etc.

5. Organizando reuniones científico-sociales o educativas propias, invitando a algunos médicos que puedan interesarse en las materias a tratar, sea como asistentes o expositores.

6. Colaborando en el financiamiento de publicaciones médicas únicas o periódicas a través de la promoción o avisaje de sus productos.

7. Estableciendo una relación contractual con algunos médicos.

* Se entiende por "industria proveedora en salud" al conjunto de empresas, habitualmente privadas y comerciales, productoras y distribuidoras de servicios o insumos necesarios para las prestaciones médicas, incluyendo a las compañías farmacéuticas, los fabricantes de equipos para diagnóstico o tratamiento (prótesis, marcapasos, sondas), los fabricantes de alimentos especiales para fines médicos, suplementos y complementos nutricionales, probióticos, prebióticos, etc. 
8. Haciendo partícipes directa o indirectamente a médicos en las actividades comerciales de la industria, ya sea como accionistas, empleados o socios de una determinada empresa o proyecto.

9. Organizando, financiando, estimulando o encomendando la participación de médicos en ensayos clínicos destinados a medir eficacia terapéutica, diseñados y controlados total o parcialmente por la misma industria. (El tema específico de los ensayos clínicos será analizado en un próximo documento).

Una relación de interés mutuo para las agrupaciones médicas y la industria es el aporte financiero que ésta realiza a los eventos científicos organizados por entidades académicas o profesionales en favor de la educación médica. La organización de los eventos científicos se beneficia porque se contribuye en el financiamiento de los costos de los eventos -que de otro modo deberían cubrir sus asistentes-, incrementando su atractivo y el número de participantes. A cambio de este apoyo financiero, las empresas obtienen un espacio para promocionar su marca y sus productos. Este tipo de apoyo a la educación médica es aceptable. Sin embargo, es imprescindible que el control académico del programa científico permanezca siempre en manos de las instituciones académicas organizadoras, asegurando la independencia científica de los contenidos de las conferencias, cursos y talleres de educación médica.

Los antecedentes y problemas antes mencionados motivan a la Academia Chilena de Medicina para proponer recomendaciones que ayuden a los médicos y a sus instituciones a regular y transparentar sus relaciones con la industria proveedora en salud, reconociendo que estas relaciones son inevitables y necesarias para el progreso de las acciones médicas que comprometen a ambas vertientes.

\section{Recomendaciones}

1. En sus relaciones personales o institucionales con la industria proveedora en salud, los médicos deben mantener una actitud crítica sobre la información que reciban, exigiendo que esté respaldada por fundamentos científicos y clínicos sólidos, independientes y evaluables. El profesional debiera poder distinguir entre la información útil para el beneficio de sus pacientes y la propaganda comercial sin respaldo científico. Los médicos deben tomar sus decisiones en forma autónoma, evitando la influencia de regalos y atenciones con fines promocionales.

2. En sus presentaciones públicas en los congresos científicos, en conferencias y en todo tipo de reuniones profesionales o académicas, los médicos participantes deben hacer transparentes, primero a los organizadores y luego al público asistente, todas sus relaciones personales con la industria, de modo que ambos puedan identificar y sopesar la presencia o influencia de eventuales conflictos de intereses. Esta declaración debiera señalar el nombre de la o las empresa(s) patrocinante(s) y el tipo de aporte o servicio que los ha vinculado durante los últimos tres años, pero no requiere explicitar el monto del aporte respectivo.

3. Una declaración pública de conflicto de intereses con la industria durante los tres años precedentes debe considerarse particularmente necesaria para quienes sean invitados a redactar guías médicas o a integrar comités profesionales destinados a tomar decisiones administrativas, tales como compra de insumos, fármacos, técnicas diagnósticas, equipos $\mathrm{u}$ otros productos propios de la industria, $\mathrm{y}$ para fijar normas clínicas o consensos de diagnóstico o tratamiento. Los participantes deben evaluar si tales conflictos inciden o no en los temas a tratar. Sus declaraciones de potenciales conflictos de intereses deben explicitarse en los documentos resultantes de la labor de estos comités.

4. Los médicos que participen en comités editoriales, grupos de trabajo o consejos de redacción de guías clínicas o manuales terapéuticos que tengan relaciones con la industria proveedora y donde pudieran existir conflictos de intereses, deben abstenerse de participar en las discusiones o recomendaciones relacionados con sus potenciales conflictos de intereses.

5. Los médicos organizadores de reuniones científicas y profesionales pueden solicitar y aceptar ayuda financiera de la industria para reuniones de educación médica de pre o postgrado, pero con la condición de mantener absoluta independencia en la elaboración del programa científico y en la selección de los docentes y expositores de dichas reuniones. Las empresas que han otorgado ayuda deben ser reconocidas y agradecidas explícitamente al comienzo y término de la reunión respectiva, pero en cualquier referencia a un producto específico debe indicarse que ella no implica el respaldo científico ni clínico de la entidad organizadora de la reunión. 
6. Los médicos deben abstenerse de recibir regalos personales de la industria. Entidades internacionales recomiendan establecer un límite máximo al monto anual que puede ser aceptado como obsequio por un médico de parte de la industria; este obsequio no debería superar un valor equivalente a tres UF anuales.

7. Las autoridades médicas que recurren a ayudas de la industria para organizar una reunión científica o profesional, deben evitar que se les relacione con la promoción de productos farmacéuticos u otros, y que la promoción de la empresa respectiva o sus productos se haga sólo mediante documentos, pero no a través de la entrega de "muestras médicas", invitaciones $\mathrm{u}$ otros obsequios.
8. Los médicos que acepten invitaciones de la industria para asistir a congresos, simposios $\mathrm{u}$ otras reuniones profesionales debieran condicionar su aceptación a que ella no los comprometa a promover, respaldar o prescribir productos de la empresa respectiva.

9. Los médicos no deben aceptar invitaciones de la industria para participar en actividades sociales, turísticas u otras que no estén directamente relacionadas con su labor profesional.

10.Es recomendable que las organizaciones médicas científicas, gremiales o de otro orden, dicten normas de conducta para sí mismas y para sus asociados que rijan sus relaciones con la industria proveedora y contemplen instancias para resolver dudas y conflictos.

** Comité Redactor del Documento Académicos Drs.: Rodolfo Armas (Presidente de la Academia), Juan Pablo Beca, Andrés Heerlein (Presidente del Comité), Miguel O’Ryan, Humberto Reyes y José Adolfo Rodríguez.

Agradecemos la colaboración de los invitados externos a la Academia: Dra. Lorna Luco y Dr. Rodrigo Salinas.

Agradecemos los aportes de los Académicos Drs.: Alejandro Goic, José Manuel López, Sergio Iacobelli, Benjamín Stockins, Ricardo Uauy, Gloria Valdés y Juan Verdaguer. 